\title{
Simulasi Aliran Dua Fase pada Campuran Air-Minyak di Pipa Horizontal dengan Parameter Termal
}

\author{
Bahrul Jalaali $^{*}$, Eli Kumolosari ${ }^{1}$ \\ ${ }^{1}$ Departemen Teknik Mesin, Fakultas Teknologi Kedirgantaraan, Institut Teknologi Dirgantara Adisutjipto, Indonesia \\ Email: Bahrul@itda.ac.id
}

Received: July 18, 2021; Accepted : August 23, 2021; Published : November 1, 2021

\begin{abstract}
A CFD study of Water-Oil flow in the horizontal pipe was conducted using the Volume-of-Fluid (VoF) multiphase model coupled with the SST $\mathrm{k}-\omega$ turbulence model scheme. This study aimed to simulate the mixture flow characteristic by takes account temperature parameter. It was numerically solved using a finite-volume model utilized in Fluent software. The simulation results compared towards experimental showed good prediction on the particular flow pattern. In this study, the thermal parameter was then solved by utilizing energy equation coupled by multiphase model. The water flow temperatures were varied in ranged of 300-340K. The results showed that temperature affected reducing the viscosity of the fluid as well as the density. Furthermore, the flow pattern changed whereby oil was above the water due to its lower viscosity and density. This study is beneficial for accessing the temperature effect on the water-oil flow as represented in the applied petroleum industry of oil-lifting.
\end{abstract}

Keywords: Water-oil, Multiphase, CFD, VoF method, Temperature

\section{ABSTRAK}

Kajian CFD mengenai aliran air-minyak pada pipa horizontal telah dilakukan dengan menggunakan model multifase Volume-of-Fluid (VOF) yang dikombinasikan dengan skema model turbulen SST $\mathrm{k}-\omega$. Kajian ini bertujuan untuk melakukan simulasi karakteristik campuran aliran dengan mempertimbangkan parameter temperature. Kasus ini diselesaikan secara numerik menggunakan model volume hingga yang digunakan pada piranti lunak Fluent. Dari hasil simulasi yang dibandingkan dengan hasil eksperimen menunjukkan prediksi yang baik terutama pada pola aliran tertentu. Pada kajian ini, parameter termal diselesaikan menggunakan persamaan energi yang dikopel dengan model multifase. Temperatur aliran air divariasikan pada rentang 300-340K. Dari hasil didapatkan bahwa temperatur berpengaruh mengurangi kekentalan dan densitas fluida. Selanjutnya, pola aliran berubah dimana minyak akan berada diatas air karena memiliki kekentalan dan densitas yang lebih rendah. Kajian ini bermanfaat untuk mengetahui pengaruh temperature pada aliran air-minyak sebagaimana ditemukan dalam aplikasi pengangkatan minyak pada industri perminyakan.

Kata Kunci: Air-minyak, multifase, CFD, metod VOF, temperatur

\section{LATAR BELAKANG}

Produksi minyak bumi di Indonesia telah mengalami penurunan dari 346 juta barel pada tahun 2009 menjadi 283 barel. Hal ini disebabkan oleh turunnya produktifitas sumur produksi yang relatif sudah tua sedangkan penemuan sumur-sumur terbaru masih terbatas [1]. Eksplorasi sumur baru memiliki kendala berupa lokasi potensi cadangan-cadangan minyak berada di dalam daerah yang relatif sulit dilakukan eksplorasi. Sehingga, salah satu alternatif untuk meningkatkan produksi minyak bumi dengan cara improved oil recovery maupun enhanced oil recovery (EOR). Secara umum, proses recovery minyak bumi dapat dibagi menjadi 3 fase yakni fase primer, sekunder dan tersier. Fase primer ialah pada saat minyak diambil dari hidrokarbon yang secara alamiah naik ke permukaan. Sedangkan fase sekunder, umumnya air dan gas akan diinjeksikan ke dalam sumur produksi untuk membantu minyak naik ke permukaan [2,3]. OR merupakan fase tersier dimana metode ini diaplikasikan setelah fase primer dan sekunder telah dilakukan dan minyak bumi masih bisa dioptimalkan untuk diambil [4]. Setelah fase primer dan sekunder, masih terdapat kurang lebih $60-80 \%$ cadangan minyak yang tersisa di dalam sumur [5]. Proses EOR dapat diklasifikasikan berdasarkan jenis reservoirnya yakni konvensional dan non-konvensional. Pada reservoir konvensional, proses EOR yang digunakan adalah steam-flooding, cyclic steam injection dan in-situ combustion. Sedangkan untuk reservoir non-konvensional pada umumnya digunakan proses ekstrasi uap dan steam assisted gravity drive. Kesuksesan proses EOR berdasarkan pada beberapa parameter termasuk kesesuaian dengan reservoir, efisiensi proses recovery, ketersediaan fluida untuk injeksi serta biaya [3]. Salah satu metode yang umum digunakan dalam proses EOR adalah termal-EOR dimana salah satunya adalah steam-flooding. Proses ini ialah menginjeksikan steam ke dalam sumur produksi minyak untuk mengurai viskositas minyak dengan proses termal sehingga dapat lebih mudah untuk naik ke permukaan. Pada kasus ini, steam tidak hanya 
memanaskan minyak namun juga perpindahan panas terjadi di lingkungan sekitarnya yakni tanah dan bebatuan. Hal tersebut mengakibatkan adanya heat loss, dimana steam akan terkondensasi [3, 6-8]. Adanya kondensasi tersebut dapat menyebabkan pencampuran air dan minyak. Hal ini mengakibatkan biaya operasional yang meningkat karena proses pengambilan minyak menjadi lebih banyak akibat campuran air. Sehingga, fasilitas dehydration dibutuhkan untuk memisahkan minyak dan air [5]. Berdasarkan hal tersebut, perlu dilakukan sebuah kajian mengenai perilaku aliran multifase campuran air-minyak sehingga dapat dilakukan pemilihan parameter sifat fisis pada saat proses EOR ke dalam sumur produksi.

Penelitian mengenai EOR telah dilakukan oleh Huang et al. dimana parameter penurunan nilai viskositas termal dan distilasi steam merupakan prinsip pada mekanisme EOR [9]. Selain itu, parameter reaksi derajat crack aquatermal antara steam dan minyak mentah menjadi perhatian juga. Kovcek dalam penelitiannya menyatakan bahwa dalam proses steam-flooding memiliki tantangan pada besarnya jumlah air dan karbondioksida yang dihasilkan memiliki dampak lingkungan yang tidak baik. Parameter penting dalam mekanisme ini adalah pencairan konsentrasi minyak dengan adanya peningkatan temperatur. Pada prosesnya, steam-flood akan kehilangan panas, terkondensasi dan bercampur dengan minyak [10]. Zhengbin et al. mengkaji mengenai peningkatan produksi minyak dengan termal-EOR dengan kajian numerik. Pada kajiannya didapatkan nilai temperatur optimum injeksi [11]. Studi ekperimental dan komputasi dinamika fluida (CFD) pada proses termal EOR dilakukan oleh Askarova et al. Pada hasil studinya didapatkan bahwa solusi numerik dapat melakukan validasi dan kajian parametrik untuk kasus fenomena termal-EOR [12]. Wu Sunghong dalam kajiannya menyatakan proses steam-flood yang sukses pada reservoir dengan karakter permabilitas rendah dan minyak ringan. Dalam kajiannya dikemukakan bahwa parameter ekspansi termal, karakter penguapan, wettability dari minyak maupun air pada permukaan batu, interfacial tension, dan gravitasi merupakan parameter yang dikaji dalam melihat performa dari proses steam-flooding [13]. Valencia et al. dalam kajiannya berhasil melakukan simulasi dengan model pada injeksi droplet dengan dispersi kimia pada aplikasi EOR. Dalam penelitiannya, dikemukakan bahwasanya simulasi numerik dapat memberikan hasil secara akurat dan memiliki kelebihan kemudahan jika dibandingkan dengan hasil eksperimen [14].

Pada penelitian sebelumnya, masih sedikit yang membahas mengenai perilaku aliran minyak-air saat berada dalam kondisi temperatur yang bervariasi dengan kajian numerik. Pada penelitian ini akan dikaji mengenai perilaku aliran multifase pada minyak-air dengan variabel temperatur air yang divariasikan dalam pipa. Hal tersebut dimaksudkan untuk mengetahui parameter-parameter yang terbentuk pada saat campuran saturasi uap panas ataupun air dengan minyak. Sehingga, dalam proses steam-flooding dapat dilakukan optimasi berdasarkan sifat-sifat pada perilaku aliran. Metode numerik yang digunakan berbasis metode volume hingga. Sedangkan untuk interface multifase akan didefinisikan dengan metode berbasis volume-offluid yang selanjutnya akan dipadukan dengan persamaan energi. Hasil dari penelitian ini berupa kajian fisis pada fenomena aliran campuran minyak dan air dengan variabel temperatur. Selain itu, penelitian ini akan menyajikan sebuah model simulasi numerik untuk melakukan simulasi kasus termal-multifase pada campuran minyak-air. Diharapkan, dengan adanya metode numerik ini didapatkan korelasi yang selaras antara hasil eksperimen dan numerik sehingga dapat memberikan suatu metode simulasi dalam melakukan kajian parametrik pada fenomena termal-multifase khususnya pada kasus campuran minyak dan air.

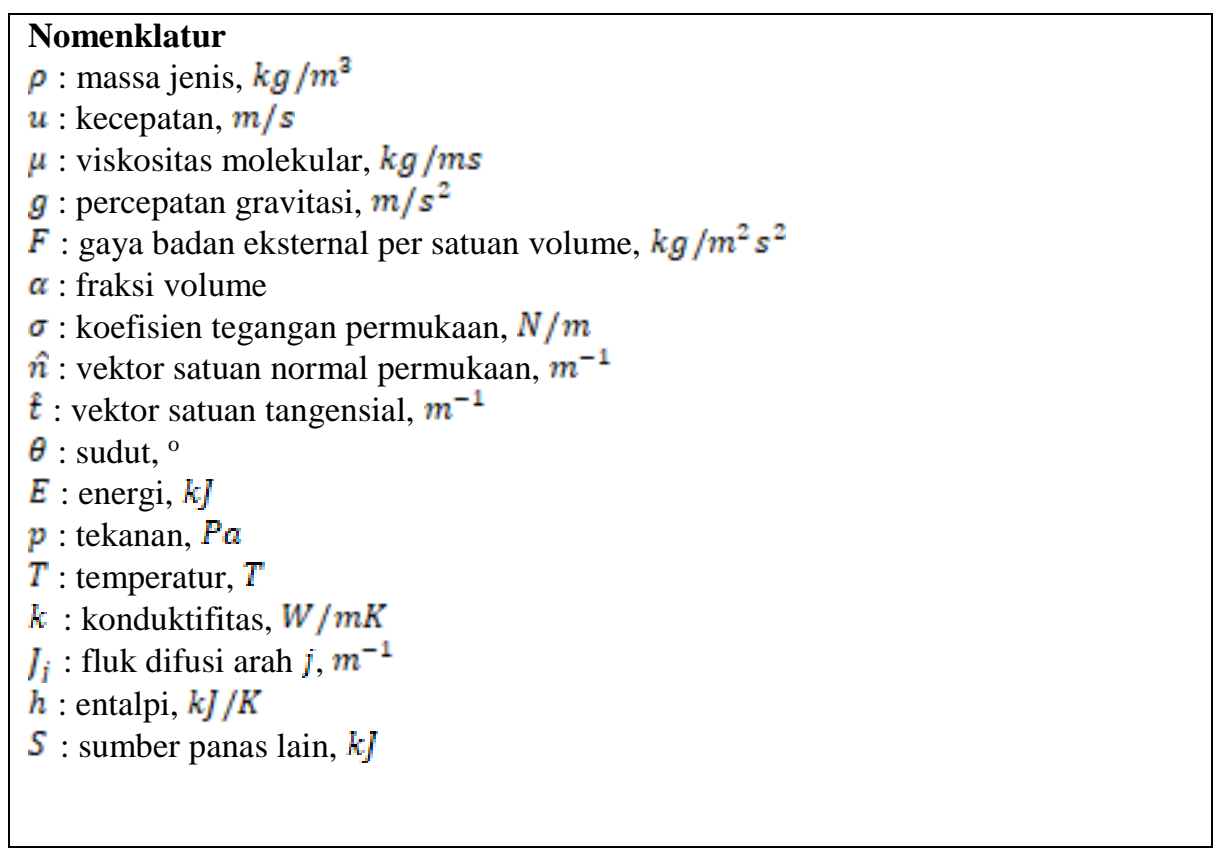




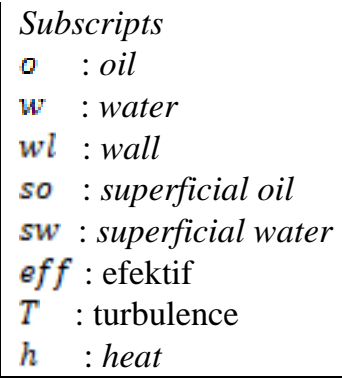

\section{METODE PENELITIAN}

\subsection{Model CFD}

Model volume-of-fluid ( $\mathrm{VoF}$ ) untuk kasus multifase digunakan pada penelitian ini. Penggunaan model ini berdasarkan acuan referensi [15-17] yang menggunakan model yang sama untuk kasus air-minyak. Campuran air-minyak pada skema multifase akan mengikuti persamaan konservasi yang ditunjukkan pada persamaan (1), (2) dan (3).

$$
\begin{aligned}
& \text { Konservasi massa: } \frac{\partial(\rho)}{\partial t}+\nabla \cdot(\rho \cdot u)=0 \\
& \text { Konservasi momentum : } \frac{\partial}{\partial t}(\rho u)+\nabla \cdot(\rho u \cdot u)=-\nabla p+\nabla \cdot\left[\mu\left(\nabla u+\nabla u^{T}\right)\right]+\rho g+F \\
& \text { Konservasi energi : } \frac{\partial}{\partial t}(\rho E)+\nabla \cdot(u(\rho E+p))=\nabla \cdot\left(k_{\text {eff }} \nabla T-\sum_{j} h_{j} J_{j}+\left(\overline{\bar{\tau}}_{\text {eff }} \cdot u\right)\right)+S_{h} \\
& \text { Persamaan VoF: } \frac{\partial\left(\rho_{0} \alpha_{p}\right)}{\partial t}+\nabla \cdot\left(\rho_{0} \alpha_{0} u\right)=0
\end{aligned}
$$

Pada tracking interface fase minyak-air akan dilakukan dengan menyelesaikan persamaan VoF dimana air akan diatur sebagai fase primer dan minyak sebagai fase sekunder (Persamaan (4)). Tiap-tiap sifat fisis seperti massa jenis dan viskositas, akan diberi bobot sesuai fraksi volumenya. Persamaan untuk merepresentasikan sifat fisis tiap fase ditunjukkan pada persamaan (5) dan (6) yang akan diselesaikan dalam domain volume atur. Total fraksi volume untuk fase primer dan sekunder bernilai 1 (persamaan (7)). Adapun gaya badan, $\boldsymbol{F}$, pada kasus ini merupakan kontribusi adanya gaya-gaya permukaan. Pada model simulasi ini akan mengacu bentuk persamaan gaya permukaan kontinum Brackbill et al. [18] yang ditunjukkan pada persamaan (8), (9). Pada bagian dinding pipa, akan diterapkan asumsi wall adhesion yang direpresentasikan pada persamaan (10). Dimana merupakan satuan vector normal dan tangensial relatif terhadap dinding. Sedangkat sudut kontak, akan diasumsikan steady dengan nilai $175^{\circ}$ mengacu referensi [16,17]. Adapun pada penyelesaian kasus multifase, model turbulen shear stress transport (SST) k- $\omega$ model akan digunakan pada penelitian ini.

$$
\begin{aligned}
& \rho=\alpha_{0} P_{0}+\alpha_{W} P_{W} \\
& \mu=\alpha_{0} \mu_{0}+\alpha_{W} \mu_{W} \\
& \alpha_{W}+\alpha_{0}=1 \\
& \boldsymbol{F}=\sigma K \frac{\rho \Gamma \omega_{g}}{\frac{1}{2}\left(\rho_{Q}+p_{W}\right)} \\
& \kappa=\nabla \times \frac{\nabla s_{g}}{\left\|\nabla s_{g}\right\|} \\
& \hat{n}=\hat{n}_{w l} \cos \theta_{w l}+\hat{t}_{w l} \sin \theta_{w l}
\end{aligned}
$$

\subsection{Geometri, pengaturan simulasi dan kondisi batas}

Pada simulasi ini aliran air-minyak akan dipisahkan menjadi 2 inlet. Kemudian, menggunakan sambungan T, kedua zat tersebut dialirkan dalam satu pipa. Representasi geometri simulasi ditunjukkan pada gambar 1. Pipa inlet memiliki ukuran diameter $13 \mathrm{~mm}$ inci sedangkan pipa utama memiliki ukuran $26 \mathrm{~mm}$ dengan panjang pipa $1000 \mathrm{~mm}$. Adapun pada batas antara sambungan T akan diberikan plat dengan tebal $5 \mathrm{~mm}$ utnuk memisahkan kedua aliran. Air dan minyak memiliki sifat-sifat yakni $\rho_{0}: 910 \mathrm{~kg} / \mathrm{m}^{2}, \rho_{V y}: 998$ $\mathrm{kg} / \mathrm{m}^{2}, \mu_{0}: 5000 \mathrm{cP}$ dan $\mu_{W}: 1 \mathrm{cP}$. Adapun untuk parameter interfacial tension pada air-minyak akan diatur $\sigma: 0,02 \mathrm{~N} / \mathrm{m}$. Temperatur minyak akan diatur $300 \mathrm{~K}$, sedangkan temperatur air akan divariasikan pada 
rentang 300-340K. Pada penelitian ini akan dibatasi pada simulasi pada aliran minyak-air dengan kriteria massa jenis mendekati identik atau matched density.

Mesh quadliraterals digunakan pada penelitian ini dengan ukuran elemen divariasikan dari $4 \mathrm{~mm}$ dan diperkecil dengan faktor 2 hingga $1 \mathrm{~mm}$ untuk tujuan analisis sensivitas. Adapun, pemilihan nilai elemen kecil pada penelitian ini akan diatur kecil sehingga boundary layer dapat diamati dengan jelas dengan mempertimbangkan parameter $y^{+}$. Kecepatan superficial air akan diatur $0,61 \mathrm{~m} / \mathrm{s}$ dan minyak $0,12 \mathrm{~m} / \mathrm{s}$. Kecepatan ini dipilih berdasarkan referensi Shi et al [19], dimana pada kondisi tersebut akan didapatkan pola aliran oil lumps in water. Aliran tersebut dipilih karena akan lebih jelas dalam memberikan gambaran perubahan/transisi ke aliran stratified pada saat terjadi perubahan sifat fluida yang menyebabkan pola aliran juga berubah. Kondisi batas yang digunakan pada outlet adalah pressure outlet dan pada dinding pipa diterapkan kondisi no-slip. Nilai dari sudut kontak dinding dengan cairan akan diatur $\theta_{w \mathbb{l}}=175^{\circ}[16,17]$. Aliran akan diatur dengan kondisi transient dan diselesaikan dengna algoritma pressure-based dan skema VoF ekplisit. Skema PRESTO! dan SIMPLE digunakan unutk menyelesaikan interpolasi tekanan dan pressure-velocity coupling. Pada persamaan momentum, akan diterapkan penyelesaian dengan skema upwind orde 1. Karena temperatur akan mengakibatkan perubahan nilai viskositas baik pada minyak dan air, maka nilai sifat-sifat fluida akan dimodifikasi di dalam FLUENT. Dengan menggunakan fitur user defined input, nilai-nilai temperature dan viskositas akan disesuaikan. Sehingga, akan didapatkan hasil yang dinamis. Hasil dari simulasi akan dibandingkan dengan hasil eksperimen [19] dalam proses benchmarking.
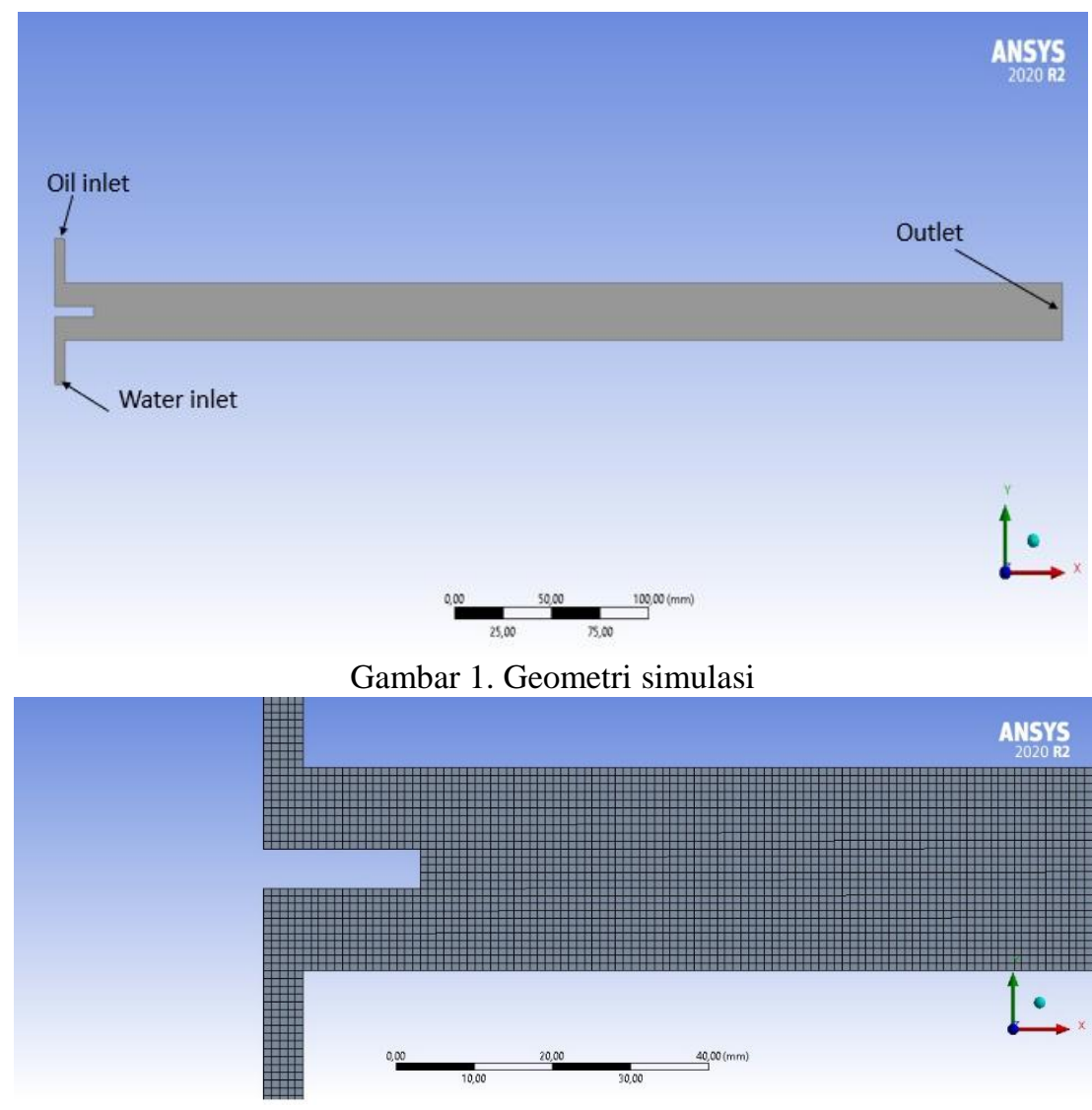

Gambar 2. Representasi meshing pada geometri

\section{HASIL DAN PEMBAHASAN}

\subsection{Hasil Simulasi Pola Aliran}

Tahap awal simulasi dilakukan dengan uji sensivitas grid. Pada penelitian ini terdapat 3 variabel grid yakni ukuran elemen $4 \mathrm{~mm}, 2 \mathrm{~mm}$ dan $1 \mathrm{~mm}$. Parameter acuan hasil mengacu pada hasil eksperimen Shi et al [19] pada kecepatan superficial minyak dan air diatur $U_{s o}=0,12 \mathrm{~m} / \mathrm{s}$ dan $U_{s w}=0,61 \mathrm{~m} / \mathrm{s}$ dengan volume fraksi minyak (oil hold-up) acuan sebesar 0,33 [16-19]. Dari hasil simulasi didapatkan untuk variasi grid 4mm, $2 \mathrm{~mm}$ dan $1 \mathrm{~mm}$ didapatkan nilai fraksi minyak sekitar 0,301-0,307 (Tabel 1). Sehingga, baik untuk grid $4 \mathrm{~mm}, 2 \mathrm{~mm}$ dan $1 \mathrm{~mm}$ didapatkan hasil yang mirip dengan nilai galat sekitar 6,9\%-8,7\%\%. Hasil ini memiliki perbedaan dengan eksperimen yang diakibatkan, salah satunya oleh efek domain geometri. Pada 
Simulasi Aliran Dua Fase pada Campuran Air-Minyak di Pipa Horizontal dengan Parameter Termal

kasus aliran, pola aliran akan sensitif terhadap geometri dimana 2D tidak akan bisa menggambarkan secara keseluruhan fenomena 3D. Akan tetapi, meski memiliki perbedaan, namun metode yang digunakan pada penelitian ini sudah dapat dianggap valid sehingga pada penelitian selanjutnya, geometri akan dilanjutkan ke 3D dengan pengaturan simulasi yang sama. Selain itu, efek tegangan permukaan, sudut kontak, interaksi dengan dinding, juga menjadi penyebab perbedaan hasil simulasi dengan eksperimen.

Adapun, pada ukuran grid $1 \mathrm{~mm}$ memiliki nilai $y^{+}$yang paling kecil, dimana akan lebih jelas dalam menangkap fenomena lapis batas. Selanjutnya, untuk mendapatkan bukti akurasi tangkapan hasil lapis batas, analisis secara visual dilakukan untuk mendapatkan pola aliran yang sesuai. Pada kasus ini variasi grid $1 \mathrm{~mm}$ dapat menampilkan visualisasi yang paling mendekati yakni pola aliran oil lumps in water (OLP) ditunjukkan gambar 3a. Pada gambar tersebut, di bagian eksperimental warna cerah merupakan minyak dan warna gelap adalah air. Sedangkan pada representasi hasil simulasi CFD, warna biru menunjukkan fase minyak, merah merupakan air dan warna lain menunjukkan adanya fase campuran. Sehingga, disimpulkan bahwa nilai grid $1 \mathrm{~mm}$ paling optimal dan akan digunakan pada simulasi ini.

Tabel 1. Hasil benchmark dari nilai $y^{+}$dan fraksi volume minyak.

\begin{tabular}{ccc}
\hline Ukuran grid & Perhitungan $\left(y^{+}\right)$ & Fraksi volume rata-rata \\
\hline $1 \mathrm{~mm}$ & 1,02 & 0,301 \\
$2 \mathrm{~mm}$ & 15,8 & 0,307 \\
$4 \mathrm{~mm}$ & 30,5 & 0,307 \\
\hline
\end{tabular}

Adapun berdasarkan hasil simulasi, telah didapati hasil visual yang cukup akurat mengikuti mapping pola aliran [19] (Gambar 3b). Sedangkan untuk grafik fraksi volume minyak rata-rata terhadap waktu atau liquid hold-up minyak terhadap waktu ditunjukkan pada gambar 4. Dari grafik tersebut dapat diamati bahwa minyak akan berada pada fraksi yang lebih kecil dibandingkan dengan air. Hal ini disebabkan karena massa jenis dari air yang lebih berat dibandingkan dengan minyak serta kecepatan superficial air yang relatif lebih cepat. Meski dari segi rasio viskositas, minyak memiliki nilai jauh lebih tinggi, namun karena rasio kecepatan superficial juga lebih tinggi, maka minyak berapa pada batas diatas air. Hal ini yang mengakibatkan pola aliran oil lumps in water (OLP).

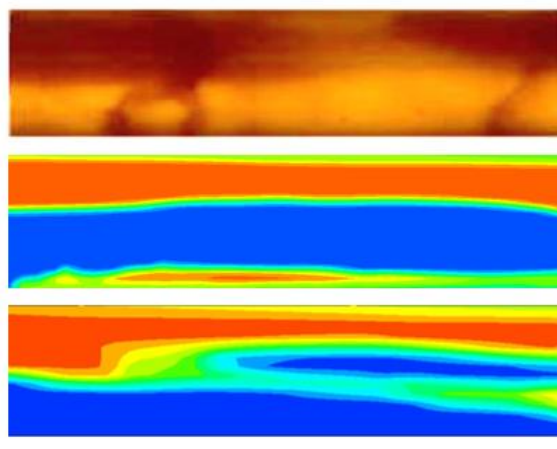

Experimental Result

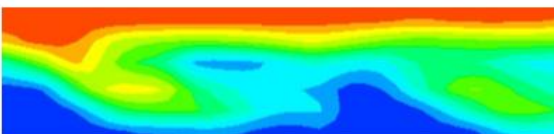

$4 \mathrm{~mm}$ grid size

(a) 


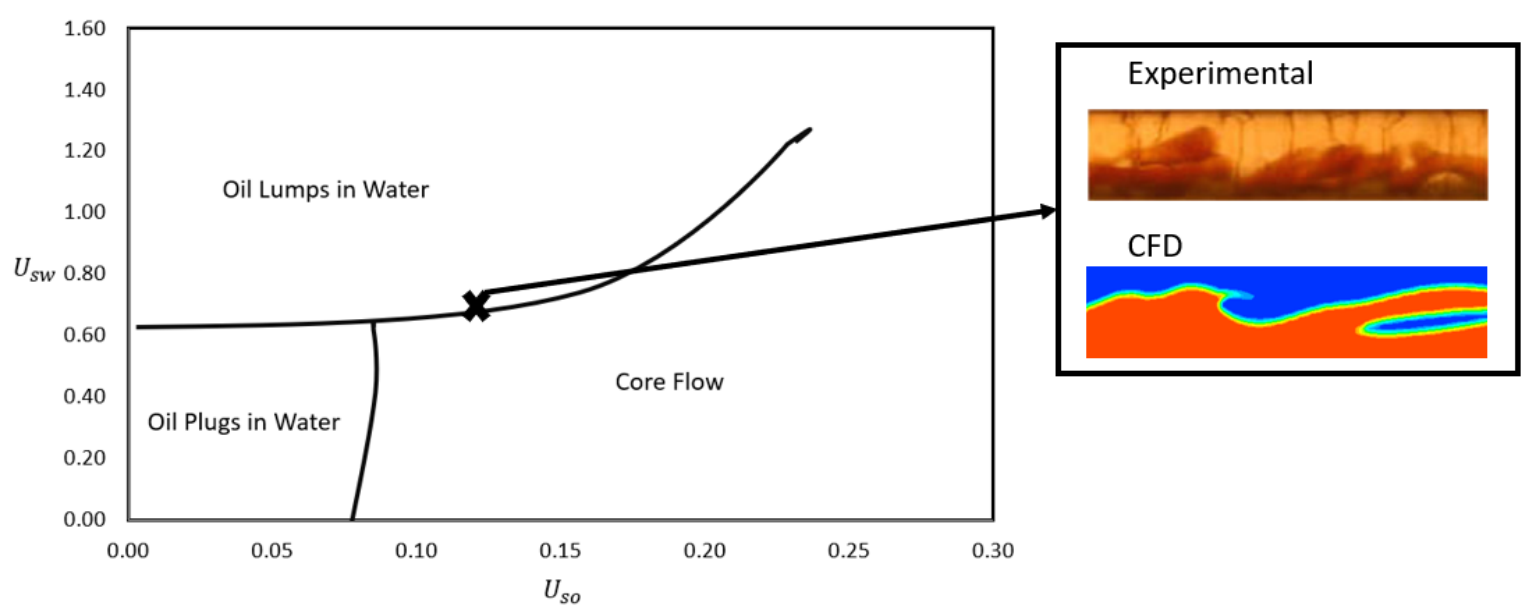

(b)

Gambar 3. Hasil simulasi (a) benchmark berdasarkan jumlah grid (b) perbandingan eksperimental dan CFD untuk grid $1 \mathrm{~mm}$.

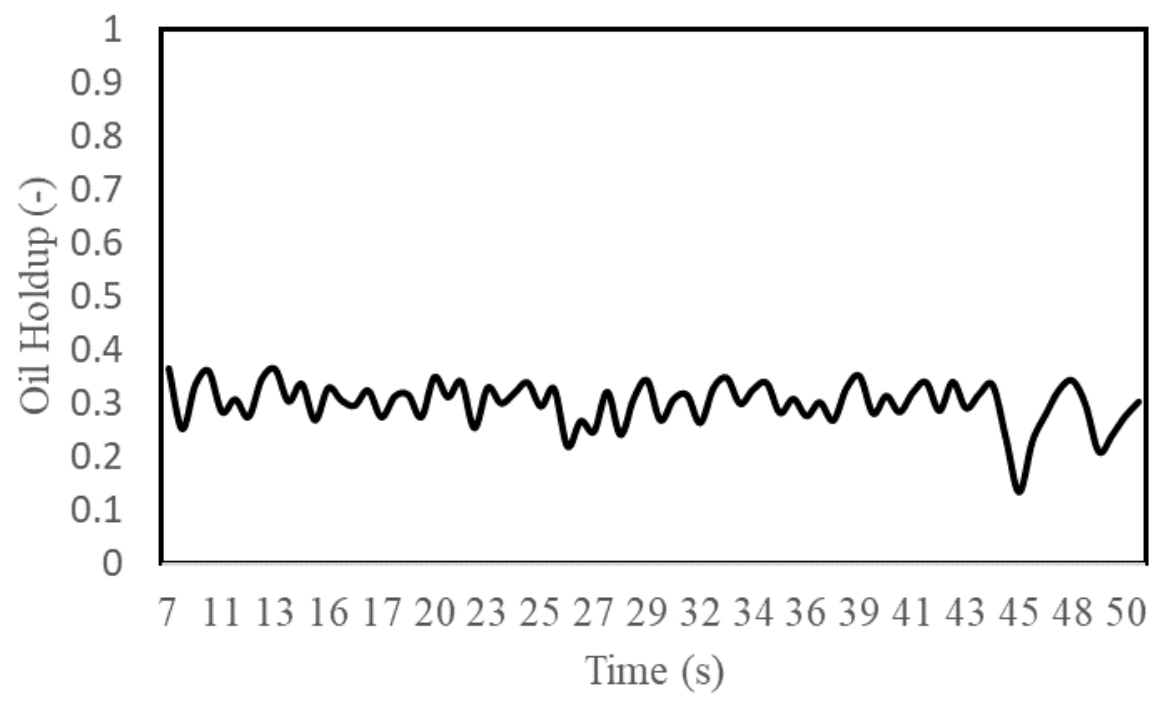

Gambar 4. Hasil hold-up minyak dalam aliran

\subsection{Parameter Temperatur}

Pada penelitian ini, variasi nilai temperatur aliran air akan diatur pada 300K, 320K dan 340K. Dari hasil simulasi, didapatkan pola aliran yang berubah seiring dengan kenaikan temperatur. Hasil representasi aliran ditunjukkan pada gambar 5 waktu 10s, 50s dan 100s. Pada variasi temperature 300K, pola aliran yang terbentuk untuk tiap satuan waktu adalah OLP dan sesuai dengan flow map regime. Di sisi lain, sifat-sifat fisis seperti densitas dan viskositas pada fluida sangat sensitif terhadap perubahan temperatur [20]. Dimana, dengan peningkatan temperatur akan mengurangi nilai-nilai sifat tersebut. Tak tekecuali pada viskositas, dimana suatu cairan akan turun nilai kekentalannya seiring dengan peningkatan nilai temperatur [20]. Hal ini selaras dengan hasil pola aliran yang didapatkan pada simulasi CFD. Dengan meningkatnya nilai temperatur, maka nilai viskositas akan turun secara drastis pada aliran minyak. Hal ini menyebabkan tegangan geser dan gaya gesek antar fase dan dinding akan berkurang juga. Sehingga, aliran minyak akan lebih mudah mengalir terbawa oleh aliran air seiring dengan penurunan rasio viskositas antara minyak dan air. Selanjutnya, pola aliran yang terbentuk akan menghasilkan stratified flow. Dalam hasil simulasi juga teramati bahwasanya seiring dengan peningkatan nilai temperatur, maka pola aliran stratified akan lebih smooth.

Dari hasil simulasi CFD, viskositas minyak akan turun dari $5 \mathrm{cP}$ menjadi sekitar 2cP. Meski demikian, rasio viskositas antara miyak dan air masih dianggap tinggi. Sebagaimana ditunjukkan pada hasil gambar $5 \mathrm{~b}$ dan $5 \mathrm{c}$, berdasarkan pengamatan visual fraksi volume minyak yang mengalir pada variasi $340 \mathrm{~K}$ lebih tinggi dibangingkan dengan variasi $300 \mathrm{~K}$ maupun $320 \mathrm{~K}$. Hal ini karena, pada variasi $340 \mathrm{~K}$, nilai viskositas akan turun dan memudahkan aliran untuk mengalir seiring dengan menurunnya nilai tegangan permukaan, 
Simulasi Aliran Dua Fase pada Campuran Air-Minyak di Pipa Horizontal dengan Parameter Termal

tengangan antar fase dan dinding pipa. Ditambah dengan adanya efek gravitasi dan kekentalan, maka aliran minyak akan menekan air di bawahnya. Oleh karena itu, pada variasi $340 \mathrm{~K}$ memiliki fraksi volume minyak yang lebih tinggi dibandingkan dengan variasi $320 \mathrm{~K}$ dan $300 \mathrm{~K}$.

Dari hasil tersebut, dapat dikaji bahwa persamaan numerik dalam kasus aliran minyak-air dengan penambahan parameter temperatur dapat diselesaikan dengan baik mengguanakn CFD. Selain itu, persamaan model multifase VoF dikombinasikan dengan persamaan energi juga dapat menghasilkan hasil yang cukup untuk merepresentasikan fenomena fisis.
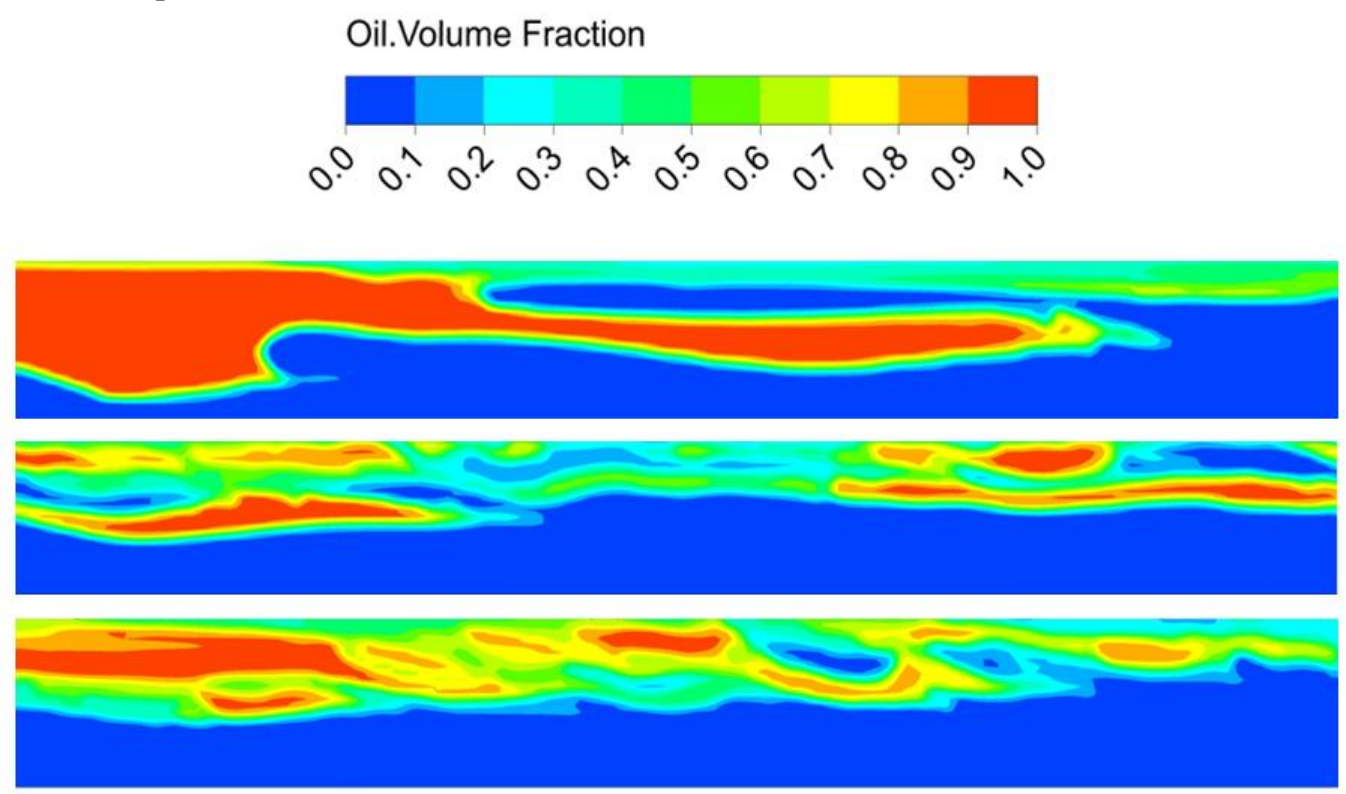

(a)

\section{Oil.Volume Fraction}
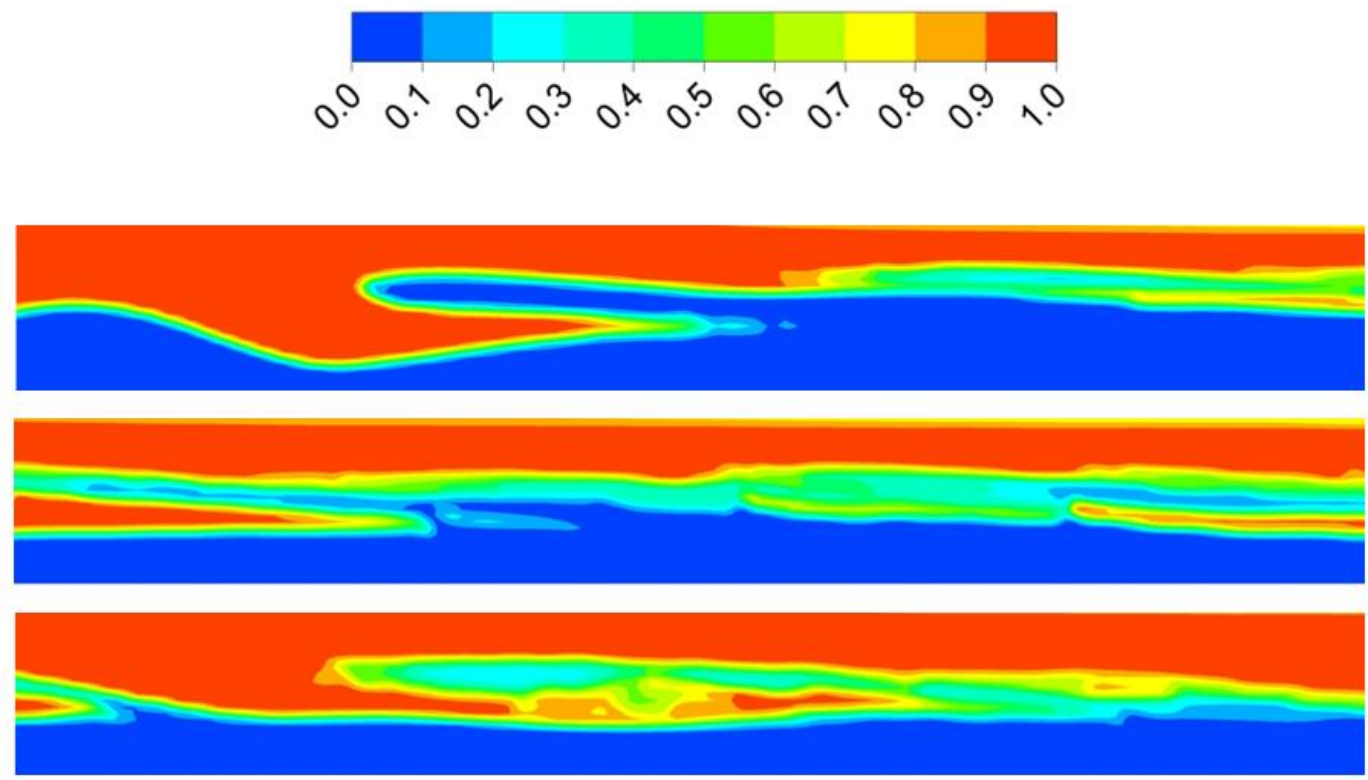

(b) 


\section{Oil.Volume Fraction}
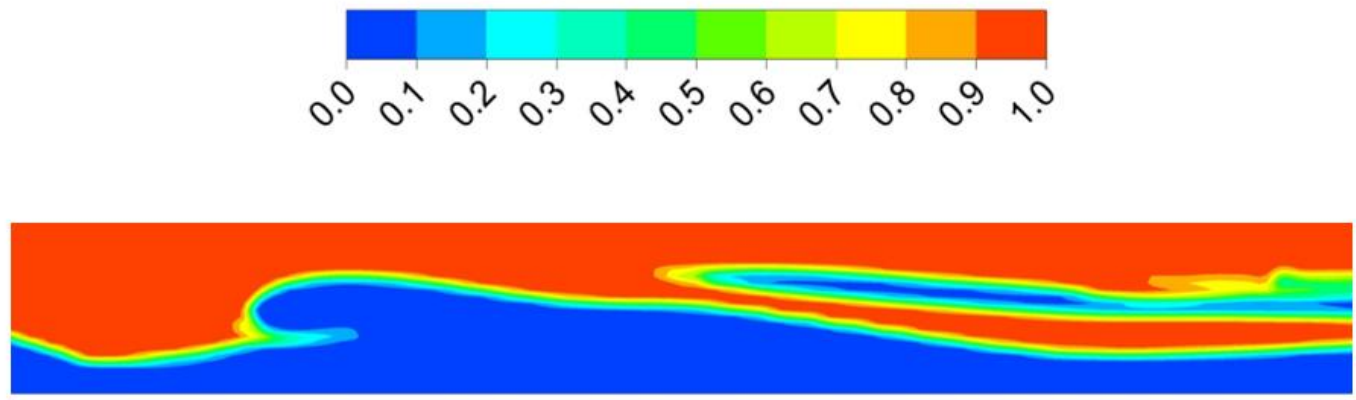

$300 \mathrm{~K}$

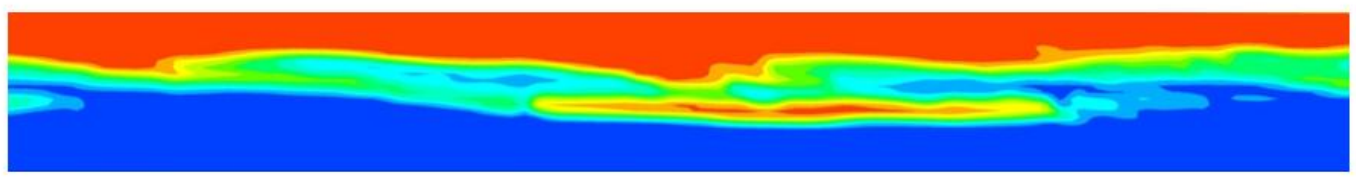

$320 K$

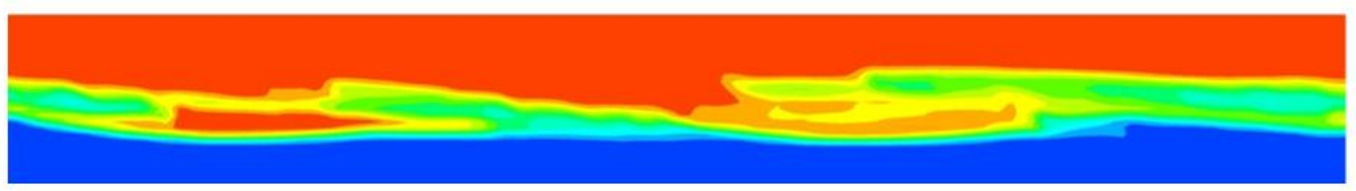

(c)

Gambar 5. Pola aliran terhadap variasi temperatur untuk tiap satuan waktu. (a) 5s (b) 50s (c) 100s.

\section{KESIMPULAN}

Simulasi aliran air-minyak pada pipa horizontal telah dilakukan secara numerik dan didapatkan hasil yang memadai dari segi validasi. Selanjutnya, hasil simulasi pada variasi temperatur kasus aliran air-minyak pada pipa horizontal didapatkan kesimpulan yang akan dirangkum sebagai berikut:

1. Hasil validasi menunjukkan deviasi hasil sekitar $10 \%$. Hal ini menunjukkan bahwa metode numerik yang digunakan telah memadai namun masih terdapat kekurangan dan fenomenafenomena yang tidak dapat ditangkap mengingat domain penelitian terbatas 2 dimensi.

2. Dari hasil simulasi, pola aliran OLP berhasil disimulasikan secara visual dan mendapatkan hasil yang memuaskan. Dimana tingkat kemiripan antara hasil eksperimen dan hasil CFD memiliki kermiripan yang cukup tinggi. Selain itu, penambahan parameter temperatur juga dapat diselesaikan dengan memuaskan menggunakan CFD.

3. Distribusi temperatur pada pola aliran dapat dihasilkan dan digambarkan melalui kajian numerik CFD. Darisini dapat ditelaah bahwa temperatur akan menurunkan nilai viskositas aliran. Sehingga, pola aliran yang terobservasi akan berubah dari pola oil lumps in water menjadi stratified flow.

\section{UCAPAN TERIMA KASIH}

Penelitian ini merupakan bagian dari skema penelitan dosen pemula tahun 2020/2021 Kementrian Pendidikan dan kebudayaan dan pendanaan bersumber dari bidang penguatan riset dan pengambangan, Kementrian Ristek dan Teknologi/Badan Riset dan Inovasi Nasional dengan nomor 01/K.2.2/DikLPPM/VI/2021.

\section{DAFTAR PUSTAKA}

[1] Ministry of Energy and Mineral Resource (2020), Handbook of Energy and Economic Statistic of Indonesia 2019, Ministry of Energy and Mineral Resource

[2] G. Glatz, "A Primer On Enhanced Oil Recovery." Physics 240, Stanford University, Fall 2013.

[3] Satter, A., \& Iqbal, G. M. (2015). Reservoir Engineering: The Fundamentals, Simulation, and Management of Conventional and Unconventional Recoveries. In Reservoir Engineering: The Fundamentals, Simulation, and Management of Conventional and Unconventional Recoveries. https://doi.org/10.1016/C2013-0-13485-X 
Simulasi Aliran Dua Fase pada Campuran Air-Minyak di Pipa Horizontal dengan Parameter Termal

[4] Green, Don. W., Willhite, P. (1998). Enhanced Oil Recovery, SPE Textbook Series.

[5] A. Z. Abidin, T. Puspasari, and W.A. Nugroho, "Polymers For Enhanced Oil Recovery Technology," Procedia Chem. 4, 11 (2012).

[6] Goyal, K. L., \& Kumar, S. (1989). Steamflooding for Enhanced Oil Recovery. Developments in Petroleum Science, 17(PB), 317-349. https://doi.org/10.1016/S0376-7361(08)70463-1

[7] Johannes Fink (2015), Petroleum Engineer's Guide to Oil Field Chemical and Fluid (2nd edition), Elsevier.

[8] Vladimir Alvarado \& Eduardo Manrique (2010), Enhanced Oil Recovery. Elsevier. https://doi.org/10.1016/C2009-0-30583-8

[9] Huang, S., Cao, M., \& Cheng, L. (2018). Experimental study on the mechanism of enhanced oil recovery by multi-thermal fluid in offshore heavy oil. International Journal of Heat and Mass Transfer, 122, 1074-1084. https://doi.org/10.1016/j.ijheatmasstransfer.2018.02.049

[10] Mokheimer, E. M. A., Hamdy, M., Abubakar, Z., Shakeel, M. R., Habib, M. A., and Mahmoud, M. (September 14, 2018). "A Comprehensive Review of Thermal Enhanced Oil Recovery: Techniques Evaluation." ASME. J. Energy Resour. Technol. March 2019; 141(3): 030801. https://doi.org/10.1115/1.4041096

[11] Zhengbin Wu, Huiqing Liu, and Xue Wang, 3D Experimental Investigation on Enhanced Oil Recovery by Flue Gas Coupled with Steam in Thick Oil Reservoirs, Energy \& Fuels 201832 (1), 279-286 DOI: 10.1021/acs.energyfuels.7b03081

[12] Askarova, A., Turakhanov, A., Markovic, S., Popov, E., Maksakov, K., Usachev, G., Karpov, V., \& Cheremisin, A. (2020). Thermal enhanced oil recovery in deep heavy oil carbonates: Experimental and numerical study on a hot water injection performance. Journal of Petroleum Science and Engineering, 194(April), 107456. https://doi.org/10.1016/j.petrol.2020.107456

[13] Shuhong, W., Key, S., Company, P., \& Min, H. (2011). SPE 145005 A Case Study: A Successful Steam Flooding Project to Enhance O il Recovery of Low-permeability, Light-oil Waterflooding Reservoir Chunli , Daqing Oil Company, Shen Dehuang, RIPED of PetroChina Company

[14] Valencia, J. D., Mejía, J. M., Ocampo, A., \& Restrepo, A. (2019). Modelling dispersed chemical droplets injection in the gas stream for EOR applications. Society of Petroleum Engineers - SPE Reservoir Characterisation and Simulation Conference and Exhibition 2019, RCSC 2019. https://doi.org/10.2118/196620-ms

[15] Deendarlianto, M. Andrianto, A. Widyaparaga, O.Dinaryanto, Khasani, Indarto, "CFD studies on the gas-liquid plug two-phase flow in a horizontal pipe", Journal of petroleum science and engineering, Elsevier (2016)

[16] J. Shi, M. Gourma, H. Yeung, "CFD simulation of horizontal oil-water flow with matched density and medium viscosity ratio in different flow regimes", Journal of Petroleum Science and Engineering, Elsevier (2017).

[17] J. Shi, M. Gourma, H. Yeung, "A CFD study on horizontal oil-water flow with high viscosity ratio", Chemical Engineering Science, Elsevier (2021)

[18] J. Brackbill, D. B. Kothe, C. Zemach, “A continuum method for modeling surface tension”, Journal of computational physics, Elsevier, (1992)

[19] J. Shi, H. Yeung, "Characterization of liquid-liquid flows in horizontal pipes", AIChe Journal, Wiley (2016)

[20] O. Alomair, M. Jumaa, A. Alkoriem, M. Hamed, "Heavy oil viscosity and density prediction at normal and elevated temperatures", Journal of petroleum exploration and production technology, Springer (2016) 
